\title{
SOBRE A MORTE O MORRER
}

DOI: $10.22289 / 2446-922 X . V 5 N 1 A 12$

\section{Ana Lucia Moreira Sousa Soares Vania Cristine de Oliveira ${ }^{1}$}

\section{KUBLER-ROSS, K, E. (1969). SOBRE A MORTE O MORRER (7a ed.). SÃO PAULO: MARTINS FONTES.}

O livro 'Sobre a Morte e o Morrer', escrito em 1969, constituído de 278 páginas, tratase da obra mais conhecida da autora, que aborda questões a respeito do medo e do temor da morte em pacientes terminais em um hospital nos Estados Unidos. Sendo este um tema que se encontra poucas pesquisas a respeito, não tão vasto, de um conteúdo pouco explorado, é de grande importância conhecermos sobre o luto e como se dá o processo de elaboração do mesmo, embora seja um fato tão temido e evitado: a morte.

A obra possui doze capítulos, sendo estes: Capítulo I Sobre o temor da morte, II Atitudes diante da morte e do morrer, III Primeiro estágio: negação e isolamento, IV Segundo estágio: a raiva, V Terceiro estágio: a barganha, VI Quarto estágio: a depressão, VII Quinto estágio a: a aceitação, VIII Esperança, IX A família do paciente, X Algumas entrevistas com pacientes em fase terminal, XI Reações ao seminário sobre a morte e o morrer, e XII Terapia doentes em fase terminal.

A autora, no primeiro capítulo, comenta sobre o temor da morte desde os antepassados que em geral era comum em pessoas cuja cultura enxergava o fim da vida como algo insuportável e aponta que com o passar do tempo esse medo continua o mesmo. Atualmente o que modificou foi o modo como o homem vem lidando com ela. Kubler-Ross descreve que no decorrer dos anos a maneira da humanidade lidar com o luto tem mudado em alguns aspectos. Em tempos antigos o moribundo era cercado da família, até mesmo das crianças, como em um ritual de despedida, o que difere de hoje, no qual o doente é totalmente isolado da família, não levando em conta os seus sentimentos e desejos, sendo considerado pela autora como uma morte desumana.

No segundo capítulo, é abordada a questão de como a pessoa encara e encherga a morte, quando o indivíduo aceita a sua situação, assim é capaz de enfrentá-la com mais tranquilidade e harmonia. A autora traz relatos de experiências do seu trabalho em um hospital especializado em tratamento de pacientes terminais, expondo que quando a pessoa é ouvida sobre seus temores e desejos, ela tende a ter uma morte mais humana, com menos ansiedade

\footnotetext{
${ }^{1}$ Endereço eletrônico de contato: vania_cristine@hotmail.com

Recebido em 28/06/2018. Aprovado pelo conselho editorial para publicação em 14/07/2018.
}

Rev. Psicol Saúde e Debate. Dez., 2019:5(1):144-148. 
e medo, e que muitas vezes os médicos, enfermeiros, estão preocupados somente em prolongar a vida com aparelhos cada vez mais sofisticados, não levando em conta a subjetividade daquele sujeito. Destacando também a forma como o médico comunica ao paciente sobre o seu estado de saúde, segundo a autora, não se deve esconder a gravidade da doença, mas ao mesmo tempo é fundamental passar esperanças ao indivíduo.

No terceiro capítulo a autora descreve sobre o primeiro estágio do luto a negação e o isolamento, salientando que todos os cinco podem ocorrer tanto nos próprios pacientes como também aos seus familiares. Nessa fase a pessoa tenta negar a realidade que está vivendo, seria como uma defesa que a mente o corpo desenvolve para conseguir lidar coma situação.

Já na fase da raiva, no quarto capítulo o indivíduo não consegue mais negar o seu estado de saúde, e logo é tomado por um sentimento de ódio, indignação e revolta, muitas vezes tornando a convivência com familiares, equipe médica complicada, devido à hostilidade com aqueles que estão por perto.

No quinto capítulo a autora se refere ao terceiro estágio: a barganha. Aqui o paciente começa fazer várias negociações e acordos com Deus, para em troca receber a saúde restabelecida, como por exemplo "Não vou mais fazer isso!", “Vou mudar meu jeito de ser.”, etc.

No sexto capítulo Kubler-Roos menciona a quarta fase que é a depressão. Nesse momento a pessoa toma consciência de seu verdadeiro estado, é o instante em que o indivíduo passa a apresentar tristeza, isolamento e a angustia.

No sétimo capítulo, a autora descreve o quinto e último estágio: a aceitação, no qual o paciente aceita de fato sua morte, sem desespero, sem revolta, mas com paz e tranquilidade.

No oitavo capítulo é apresentado sobre o quanto a esperança pode contribuir na aceitação da doença, auxiliando na elaboração das perdas, como se fosse um combustível que gera energia e forças para continuar até o fim.

No nono capítulo a autora menciona também como é a reação da família após o diagnóstico e até mesmo após morte do ente querido, no qual ocorrem várias mudanças na rotina da família, tendo estas que se adaptar a diversas transformações em suas vidas, sendo a comunicação uma ferramenta fundamental nesse momento, pois a capacidade e o jeito de interagir vão ajudar muito nesse período tão difícil. Após a morte do paciente, é importante que os familiares sejam acolhidos por profissionais que terão uma escuta generosa, assim como o apoio e a empatia podem auxiliar bastante a diminuir os sentimentos de pesar e desespero da família.

Já no décimo capítulo, constitui uma sessão em que é abordado sobre o período em que a autora conduzia o trabalho de acolhimento e entrevistas com seus pacientes, nessa parte relata sobre as atitudes e comportamentos da equipe médica que atuava junto a ela no hospital. Segundo a autora, no início havia uma certa resistência principalmente por parte dos médicos, 
em aceitar o seu trabalho, com o passar do tempo foi mudando, sendo que alguns deles já pediam para irem visitar seus pacientes. Já as enfermeiras, muitas tinham noção dos conflitos existentes, e se empenhavam em participar dos debates. Os demais profissionais também contribuíram para os resultados positivos, destacando que a partir desse seminário houve uma melhora na aceitação da morte e no processo de elaboração do luto, tanto nos pacientes, quanto nos estudantes e familiares.

No capítulo onze, a autora apresenta sobre o comportamento dos estudantes assim como dos profissionais, que tiveram resistência em conviver tão de perto com a morte, contudo aos poucos foram se familiarizando. Já a maioria dos pacientes, gostavam da ideia de conversar sobre seus anseios e temores, isso os ajudavam a ter esperanças, fazendo com que se sentissem, por vezes, úteis em dividir esses sentimentos sabendo que estavam no findar de suas vidas. A autora também pode observar que pacientes desprovidos de condições financeiras apresentavam mais facilidade em elaborar a perda comparados aos mais ricos, a fé e a esperança também auxiliavam na aceitação.

Por fim, no último capítulo, a autora finaliza seus argumentos ao dizer que, através deste seminário e de seu trabalho de acolhimento e escuta dos pacientes, a equipe médica e de enfermagem passaram a ter um olhar diferenciado no que se refere a pessoas que estavam em processo de luto, passando a valorizar muito mais a demanda subjetiva do paciente do que somente as intervenções médicas e os cuidados físicos nos últimos instantes de suas vidas. A partir do momento que o paciente expõe seus medos, seus desejos, seus suas angustias ele finalmente se sente aliviado, e assim é capaz de ter uma morte com mais dignidade, mais harmonia e paz.

A autora menciona também que existe um instante na vida do paciente em que predomina o silêncio, é o momento em ele está preparado para a morte, nesse ponto é de fundamental importância a presença de uma pessoa que possa ficar ao seu lado até o ultimo suspirar de sua vida.

O tema abordado pela autora nessa obra é um dos assuntos mais temidos de toda a humanidade, o medo da morte. No entanto trata se de um conteúdo de extrema importância, pois traz um olhar diferenciado daquele que acostumamos a enxergar no que se refere ao processo de elaboração do luto.

Percebe-se que no decorrer da leitura, o objetivo da autora é fazer com que os pacientes em fase terminal e seus familiares pudessem ter uma escuta e um acolhimento mais humanizado no que diz respeito ao temor da morte. Pode-se dizer que esse objetivo foi alcançado, uma vez que os pacientes tiveram a oportunidade de serem acolhidos e puderam ter uma morte com mais dignidade e paz. No que concerne aos familiares houve também um desenvolvimento do processo de elaborar a perda da separação do ente querido. 
A partir desse aspecto o livro traz relatos tanto de pacientes quanto de parentes que estão vivenciando o luto. Percebe-se nessas entrevistas, sentimentos carregados de angustia, dor, arrependimentos, perdas que tiveram durante a vida e principalmente preocupações referentes ao fim da vida. Nota-se que a partir do momento em que essas pessoas começam a falar sobre esses sentimentos que os incomodam, esses indivíduos puderam vivenciar essas perdas com menos sofrimento, mesmo estando próximos da morte.

No que se refere ao quesito clareza e loquacidade, observa-se que possui uma linguagem clara e há coerência nas ideias, havendo também uma argumentação bastante consistente no qual a autora utiliza a metodologia de relatos de caso e entrevista com os pacientes. Contudo, no que se refere aos relatos e entrevistas dos pacientes em algumas partes do livro, principalmente aquelas mais extensas percebe-se um pouco cansativa a leitura.

No que tange a originalidade do tema, a autora escolheu um tema não tão conhecido e abordado, sem falar que o livro foi escrito em 1969, acredita-se que nessa época poucos autores abordaram esse tema tão incrível e extraordinário.

Quanto à contribuição da obra, destaca-se a riqueza de conteúdo que é de extremo valor e importância principalmente aos profissionais da área da saúde, enfermeiros, médicos psicólogos, em especial os que trabalham na área hospitalar, pessoas que estão vivenciando uma fase de doença que não há possibilidade de restabelecer saúde ou até mesmo familiares dos doentes que já perderam seus entes queridos.

Do ponto de vista e perspectiva do desenvolvimento psicológico, as perdas acarretam um desequilíbrio tanto físico, mental e psicoemocional, rompendo com ideias, sonhos projetos de vida e implicam que o indivíduo faça reavaliações e produzam capacidade de sustentação do ego, gerando o desafio de lidar com sentimentos de desamparo, rejeição e negação causando uma fragilidade emocional frente aos dilemas e vicissitudes da vida e da morte. Esse trabalho traz um aporte e auxilio em se tratando de elaboração de perdas, lutos e separações tanto concretas quanto subjetivas visto que a vida é repleta de surpresas, frustrações, imprevistos pois as perdas tanto subjetivas quanto concretas podem provocar a desconstrução dos desejos e anseios de narcizismo, amor eterno, poder e controle sobre a vida.

Dessa forma a avaliação no que concerne ao conteúdo geral da obra é positiva, sendo muito útil, edificante e proveitoso em vários aspectos tanto pessoal quanto acadêmico.

Esse é um texto que constitui uma sólida contribuição para os profissionais da psicologia, principalmente quem trabalha na área hospitalar devido a convivência diária com a morte e sofrimentos. Essa obra pode ser de grande relevância aos estudantes de psicologia, medicina, enfermagem e simpatizantes e admiradores da área da filosofia.

Pode ser útil também, à pessoas que estão vivendo alguma doença em fase terminal, no qual ajudaria bastante compreender e enfrentar a morte de uma maneira mais consciente, Rev. Psicol Saúde e Debate. Dez., 2019:5(1):144-148. 
ajudando a refletir que a natureza humana é limitada no que diz respeito ao desejo de finitude auxiliando a família enfrentar a perda com mais serenidade e paz.

Cabe aqui ressaltar que apesar dessa obra salientar os processos de luto dos familiares, é importante enfatizar que esse livro também pode ajudar indivíduos que tiveram outros tipos de perdas, não necessariamente a morte de um familiar, mas por exemplo separações, divórcios, perca de um sonho, de projetos que ficaram a deriva. Visto que a leitura será de grande importância para auxiliar na elaboração tanto do luto quantos das perdas e separações e assim ajudar o indivíduo desenvolver o processo normal e não patológico do luto. 